\title{
Hypertonic Saline Dextran - The Fluid Of Choice In The Resuscitation Of Haemorrhagic Shock?
}

\section{W Sapsford}

\section{Introduction}

The crystalloid - colloid debate regarding the most effective intravenous fluid for resuscitation from haemorrhagic shock has been raging over the past 60 years, and still continues without a satisfactory resolution (1). Crystalloid solutions are essentially isotonic salt solutions $(270-310 \mathrm{mOsm} / \mathrm{L})$ and have been in use since the 1800 s but their use became widespread during World War I. Normal saline or Ringer's lactate solutions currently predominate over all other fluids for intravenous volume support. Colloids, on the other hand, are large macromolecules that remain in the circulation and exert a colloid osmotic or oncotic pressure due to their molecular weight. Their size also determines how long they remain osmotically active in the circulation. Albumen, separated from plasma by Cohn in 1942, was introduced as a colloid and was used extensively in World War II. Today macromolecular solutions of albumin, dextran, hetastarch and gelatin are used, with preferences determined more by cost and marketing than for clinical indications or efficacy. Colloid solutions are normally $3-10 \%$ macromolecules in an isotonic crystalloid to prevent haemolysis. Most colloid solutions have a colloid osmotic (oncotic) pressure similar to plasma (20-30 $\mathrm{mmHg}$ ). A $6 \%$ solution of albumin is isooncotic and expands plasma volume by $80 \%$ of infused volume; $6 \%$ hetastarch is slightly hyperoncotic and $6 \%$ dextran 70 is markedly hyperoncotic $(60-75 \mathrm{mmHg}$ ) and expands plasma volume by $20-50 \%$ more than the infused volume (2-4).

The ensuing debate revolved around the physiological response to hypovolaemia. The advantage of colloids is that they are more efficient plasma expanders and cause less oedema in hypovolaemic shock, compared to crystalloids that distribute rapidly throughout the entire extracellular space with no preference for the vascular compartment. Since the extracellular space is 4-5 times larger than the plasma volume, only $10-20 \%$ of infused crystalloid remains in the circulation, requiring at least three units of crystalloid to replace each unit of shed blood - the " $3: 1$ rule" $(2,5)$. The two major disadvantages of colloids are cost and their potential complications (Table 1).

While blood and blood products have remained the mainstays of massive transfusions, they are only available in the hospital environment and there is always the risk of infection and immunological reactions. Blood substitutes, such as haemoglobin solutions, liposome encapsulated haemoglobins and perfluorocarbons are still in development and remain some years away from routine use. Thus, in recent years, attention has turned to the potential benefits of other fluids for resuscitation, in particular, hypertonic saline solutions, alone or combined with a colloid for the treatment of haemorrhagic shock. At the same time, research has questioned the traditional management of haemorrhagic shock with aggressive fluid resuscitation (based on the Wiggers (6) and Shires (7) models of controlled haemorrhage) as set out in the Advanced Trauma Life Support manual (8). The introduction of an animal model of uncontrolled haemorrhage that more closely mimics the pre-hospital clinical scenario favours hypotensive resuscitation regimen prior to the definitive control of haemorrhage in the operating theatre (9). The concept of hypotensive resuscitation was subsequently examined in Bickell's seminal clinical trial where delayed fluid resuscitation in hypotensive patients with penetrating torso injuries was found to improve outcome (10)

This review will concentrate on the resuscitation of haemorrhagic shock with one such fluid, a combination of hypertonic saline $(7.5 \%)$ and the hyperoncotic colloid dextran $70(6 \%)$, called hypertonic saline dextran or HSD. This review aims to
Sqn Ldr W Sapsford MA MB BChir FRCS RAF

Honorary Research

Fellow

Biomedical Sciences,

Defence Science and

Technology Laboratory,

Porton, Salisbury

Wiltshire,

SP4 0JQ.

\begin{tabular}{|l|l|l|l|}
\hline Colloid & Molecular weight & Half-life & Potential complications \\
\hline Albumen 5\% & 69,000 & $24-48$ hours & Infection \\
\hline Hetastarch 6\% & 450,000 & $24-36$ hours & $\begin{array}{l}\text { Reticulo-endothelial deposition with } \\
\text { unknown effects }\end{array}$ \\
\hline Dextran 70 & 70,000 & 12 hours & $\begin{array}{l}\text { Interference with cross match } \\
\text { Coagulopathy at high doses }\end{array}$ \\
\hline Polygelene & 35,000 & $4-6$ hours & Anaphylactoid reactions \\
\hline
\end{tabular}

Table 1. Potential complications of colloids. 
characterise the physiology of HSD, to look at the evidence for its efficacy in animal and cellular models and to summarise the clinical evidence for its use. The use of HSD in controlled and uncontrolled haemorrhage will be reviewed and its safety will be assessed. Finally the potential role of HSD in military and civilian environments will be discussed in terms of its advantages and disadvantages in each scenario.

\section{HSD - What is it?}

HSD, known in the UK as RescueFlow ${ }^{\circledR}$, is produced by Horizon Lifecare, a subsiduary of BioPhausia AB, Uppsala, Sweden. 1000 $\mathrm{mL}$ contains $75 \mathrm{~g}$ sodium chloride and $60 \mathrm{~g}$ dextran 70. It is hypertonic because $7.5 \%$ $\mathrm{NaCl}$ represents an osmotic load of 2400 $\mathrm{mOsm} / \mathrm{L}$ when fully dissociated and the macromolecule is hyperoncotic. Isotonic $6 \%$ dextran 70 has a molecular weight of 70,000 Daltons, approximately the same molecular weight as albumin, giving it a half life in the plasma of about 12 hours, but it produces a markedly elevated colloid osmotic pressure.

The stated therapeutic indications are the initial treatment of hypovolaemia with hypotension induced by traumatic injury. RescueFlow ${ }^{\circledR}$ comes as a clear, colourless fluid for infusion in plastic bags of PVC in aliquots of $250 \mathrm{~mL}$. It is administered as a single dose of $250 \mathrm{~mL}$ intravenously as the initial treatment after primary stabilisation of respiration and bleeding and should be given by rapid infusion over $2-5$ minutes. Treatment with RescueFlow ${ }^{\circledR}$ should be followed by immediate administration of isotonic fluids dosed according to the needs of the patient. It needs no special precautions for storage and has a shelf life of 2 years (11).

\section{Physiology of HSD}

A single aliquot of $250 \mathrm{~mL}$ HSD represents a dose of approximately $4 \mathrm{~mL} / \mathrm{kg}$ in an average man. The $7.5 \% \mathrm{NaCl}$ represents an osmotic load of $600 \mathrm{mOsm}$ and produces a theoretical $3300 \mathrm{mmHg}$ increase in transcapillary absorptive force across a perfect semi-permeable membrane at $37^{\circ} \mathrm{C}$ in a 3.5 $\mathrm{L}$ plasma volume. As the reflection coefficient of the $\mathrm{Na}+$ ion is between 0.1 and 0.3 the initial total osmotic pressure is between approximately 300 and 1000 $\mathrm{mmHg}$ (12) and a transient increase of serum osmolality of between 30-50 mOsm occurs depending on the rate of infusion. The effect of this is to create a large transmicrovascular absorptive force of at least $50-100 \mathrm{mmHg}$ and an immediate shift of fluid from the intracellular to the extracellular space occurs until osmotic equilibrium is distributed equally throughout the $14 \mathrm{~L}$ extracellular space (13). Complete distribution of the $\mathrm{Na}+$ ion occurs within 30 minutes and at this time the serum osmolality is approximately $13 \mathrm{mOsm} / \mathrm{kg}$ above baseline. The dextran 70 component is isotonic and has no effect on plasma osmolality. The plasma oncotic pressure across the capillary wall is increased by $60-$ $70 \mathrm{mmHg}$ and this partitions some of the (increased volume of) extracellular fluid into the plasma space, promotes the shift of additional intracellular fluid and prolongs the increase in plasma volume.

The physiological response to hypertonic resuscitation is remarkably rapid. Kramer et al. demonstrated that in haemorrhaged sheep that received a two minute infusion of HSD the cardiovascular changes began to improve within one minute and mean arterial pressure had normalised by the end of the infusion with a $30 \%$ increase in cardiac output compared to baseline values (14). Rapid plasma volume expansion occurs concurrently with haemodynamic improvement. An Evan's blue dye dilution technique was used to demonstrate that nearly all the expansion had occurred soon after the two-minute treatment with HSD had finished (15).

The effect of $250 \mathrm{ml}$ of this combination of hypertonicity and hyperoncosity in various animals and humans is to increase the plasma volume by at least $30 \%(14,16-19)$. Following a $2 \mathrm{~L}$ haemorrhage in a $70 \mathrm{~kg}$ patient, the administration of $250 \mathrm{~mL}$ HSD would produce a plasma volume expansion of at least $700 \mathrm{~mL}$ or 3-4 times the infused volume. To achieve the same expansion in plasma volume using an isotonic crystalline solution, such as $0.9 \% \mathrm{NaCl}$, would require an infusion of $2.8 \mathrm{~L}$. A single $250 \mathrm{~mL}$ bag of HSD can thus be regarded as providing almost the same plasma volume expansion as 3 one litre bags of normal saline - less than a tenth of the volume of isotonic fluids $(20,21)$ (Figure 1).

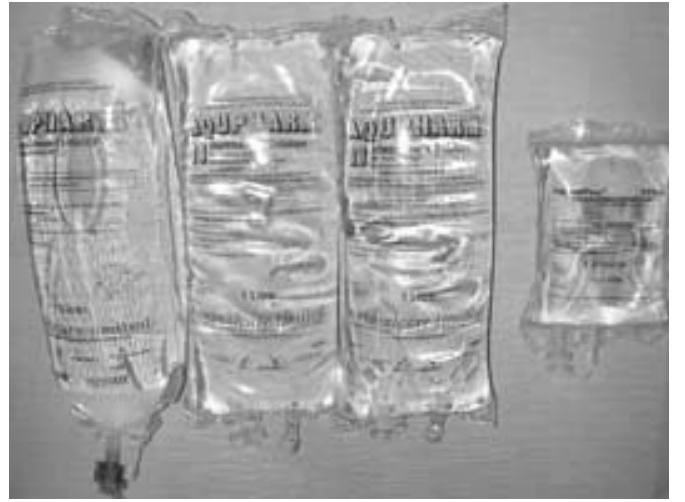

Figure 1. The volume of an isotonic crystalloid (3 L) and $H S D(250 \mathrm{~mL})$ required to replace a $1 \mathrm{~L}$ haemorrhage in an average adult.

\section{Animal research \\ Controlled haemorrhage}

The first studies of the effect of hypertonic solutions on haemodynamic stability in controlled haemorrhagic shock were performed in the 1960s. Baue and coworkers successfully used a $5.2 \%$ solution of 
$\mathrm{NaCl}$ at a dose of $5 \mathrm{ml} / \mathrm{kg}$ to resuscitate animals bled to a mean arterial pressure of $30 \mathrm{mmHg}$ (22). Velasco and associates first used $7.5 \% \mathrm{NaCl}$ in dogs in severe, controlled haemorrhagic shock at a dose of $5 \mathrm{ml} / \mathrm{kg}$ or approximately $10 \%$ of shed blood volume. $\mathrm{He}$ demonstrated restoration of haemodynamic variables and $100 \%$ long-term survival, compared to $0 \%$ in a control group resuscitated with an equal volume of normal saline (23). Nakayama et al. used 7.5\% $\mathrm{NaCl}$, at a dose of $4 \mathrm{ml} / \mathrm{kg}$ over 2 minutes, to resuscitate conscious sheep in moderate, controlled haemorrhagic shock. This group demonstrated improvements in cardiac output and mean arterial pressure compared to identical volumes of isotonic solution in their models but the effects were transient, lasting only 30 minutes or less (24). Smith and colleagues in 1985 compared $7.5 \%$ $\mathrm{NaCl}$ alone and in combination with $6 \%$ dextran 70 (HSD). They demonstrated a significantly higher and more sustained cardiac output and mean arterial pressure together with a reduced total peripheral resistance with HSD compared to hypertonic saline or dextran alone in their model of controlled haemorrhage. Significantly, the effect of the HSD on cardiovascular function was maintained for three hours (25). This sustained increase in plasma volume following HSD infusion has been measured using a dye dilution technique at fixed times following resuscitation and compared to that seen following hypertonic and isotonic saline. Normal saline is an inefficient volume expander whilst hypertonic saline and HSD expand the plasma volume by 3-4 times the infused volume. However, only HSD sustained the expansion after three hours (15). Maningas et al reported that 11.5 $\mathrm{mL} / \mathrm{kg}$ of HSD corrected the drop in blood pressure associated with severe haemorrhage in conscious pigs (17). Wade et al. then demonstrated improved and sustained haemodynamic variables following HSD infusion in the same pig model, compared to either hypertonic or normal saline (18).

The effect of HSD on survival rates has also been further investigated. Maningas et al. demonstrated $100 \%$ survival rates in a pig model of rapid but controlled exsanguination with HSD resuscitation compared to significantly reduced survival in animals given equal volumes of $7.5 \% \mathrm{NaCl}$, normal saline and $6 \%$ dextran 70 (17). Studies were subsequently performed in different controlled exsanguination models in dogs and conscious pigs and sheep that demonstrated significantly higher survival rates using HSD at doses between 4 and 11.5 $\mathrm{mL} / \mathrm{kg}$ compared to normal saline $(18,26,27)$.

HSD has also been shown to have other effects. Maningas and associates demonstrated improved organ blood flow rates in those bled animals that received a dose of $11.5 \mathrm{ml} / \mathrm{kg}$ HSD compared to normal saline. He concluded that improved blood flow to the myocardium, kidneys, liver, small intestine and pancreas could help to explain the improved survival in pigs resuscitated with HSD. He also speculated that the improved flow could attenuate later complications associated with haemorrhagic shock (28). Kreimaier et al. demonstrated that regional blood flow in the kidney, pancreas and gastric mucosa was restored by HSD with $10 \%$ dextran in severe haemorrhage and that regional blood flow in the myocardium, brain, skeletal muscle and intestines increased above base line (29). Mazzoni and co-workers, using the technique of intra-vital microscopy, went on to show that HSD improved capillary flow by reversing capillary narrowing following haemorrhage to pre-haemorrhage values by 30 minutes. By comparison $6 \%$ dextran 70 and Ringer's lactate were not as effective. They demonstrated that the endothelial cells, swollen during the ischaemic (shocked) state, were shrunk by $20 \%$ by the HSD infusion, thus causing a substantial increase in capillary blood flow $(30,31)$.

HSD also has beneficial cellular and subcellular effects in haemorrhagic shock. Chemotactic accumulation of circulating leucocytes and their adhesion to endothelial cells is a recognised feature of post-ischaemic reperfusion injury. Nolte and colleagues have shown that 4 hours after ischaemia and reperfusion of striated muscle the number of leucocytes adhering to the post-capillary venules was significantly reduced after a bolus infusion of $7.2 \% \mathrm{NaCl}$ with $10 \%$ dextran 60. Furthermore macromolecular leakage and capillary endothelial swelling was attenuated; $10 \%$ dextran alone, by comparison, was significantly less efficient in these respects (32). At a molecular level hypertonic saline dextran solutions have been shown in vitro to counteract the upregulation of $\beta_{2}$-integrins and L-selectin shedding in a dose-dependent manner thus reducing leucocyte adhesion (33). Hypertonic saline solution $(7.5 \% \mathrm{NaCl})$ has also been shown to alter favourably the post-traumatic immune response. In a mouse model of haemorrhage, resuscitation and subsequent caecal ligation and puncture, Junger et al. showed that resuscitation with hypertonic saline prevented immuno suppression and increased survival (34). The authors proposed that T-cell function was preserved by the hyperosmolar solution by bypassing signalling pathways that are usually blocked in T-cells after trauma. Finally, hyperosmolar resuscitation has been shown to reduce bacterial translocation in rats subjected to haemorrhagic shock and resuscitation (35). This may contribute to a reduction in the risk of developing multi-system organ failure following severe haemorrhage. 
Small volume resuscitation with hypertonic saline dextran has been proved, on the basis of experimental animal data, to have the following effects in controlled haemorrhage:

1.an immediate increase in systemic pressure and cardiac output, whilst vascular resistance is reduced;

2.an instantaneous increase of nutritional (capillary) blood flow;

3. a resumption of organ blood flow as seen by an increase in urinary output;

4.a reduction in post-ischaemic reperfusion injury; and

5.an increase in survival rate;

\section{Uncontrolled haemorrhage}

The conclusions presented above apply only to the use of HSD in controlled haemorrhage. In a model of controlled haemorrhage the animal is bled through a pre-implanted catheter until a set end-point; thereafter haemorrhage is terminated and resuscitation begun. A model of uncontrolled haemorrhage is considered more relevant to civilian or military trauma but the role of HSD in this situation has received much less attention. In such a model, haemorrhage continues uncontrolled during the resuscitation phase. As long ago as World War I, Cannon et al. warned that the administration of crystalloids in traumatic haemorrhage leading to shock before surgical haemostasis could have the effect of increasing haemorrhage (36). The American Surgeon General heeded this warning during World War II and hypotensive casualties, whose haemorrhage could not be externally controlled, were not aggressively treated until surgical haemostasis had been achieved (37). In 1969, Wangensteen and Ludewig reiterated this warning when they reported that large volumes of intravenous crystalloid could be deleterious in those patients whose source of haemorrhage was incompressible (38).

Bickell et al. established that, in a pig model of uncontrolled arterial haemorrhage, attempts at replacing the shed blood with three times that volume of intravenous crystalloid resulted in a significant increase in haemorrhage and a mortality rate of $100 \%$ (39). This finding ran contrary to the beneficial effect of HSD in controlled haemorrhage. The same group subsequently demonstrated that immediate administration of HSD in this model also significantly increased haemorrhage and mortality compared to untreated controls. It was noted, however, that the accentuation of haemorrhage and reduction in survival were not as great as that produced by the standard practice of attempting to replace the lost blood with three times that of crystalloid. Hypertonic saline $(7.5 \%)$ has also been shown to increase blood loss, reduce blood pressure and increase early mortality in various different rat models of uncontrolled haemorrhage $(40,41)$.

Kowalenko et al. (42) and Stern et al. $(9,43)$ then developed a model to study the concept of hypotensive resuscitation of uncontrolled haemorrhage. These groups, and others (44), have demonstrated that the mainte-nance of a hypotensive state with judicious crystalloid resuscitation causes less blood loss and increases survival and is therefore preferable to aggressive administration prior to surgical haemostasis. Doucet et al. (45) then went on to show that hypotensive resuscitation with HSD was better than no resuscitation in a pig model of uncontrolled haemorrhage. Burris et al. (46) showed that controlled hypotensive resuscitation with $7.3 \% \mathrm{NaCl}$ with $6 \%$ hetastarch increased survival compared to no resuscitation in a rat model of uncontrolled haemorrhage.

\section{Clinical research}

Hypertonic solutions are ideal for the treatment of burns and have been used in burn patients for some years now (47). Shackford et al. demonstrated that $1.5 \%$ $\mathrm{NaCl}$, used as an intra-operative fluid in elective patients undergoing surgery on the abdominal aorta, was at least as efficacious as isotonic crystalloids and that it supported the cardiovascular system with half the volume compared to the control group (48). In the mid-1980s Holcroft and co-workers trialled small volumes $(\leq 12 \mathrm{~mL} / \mathrm{kg})$ of $3 \%$ hypertonic saline intra-operatively and resuscitation with $250 \mathrm{~mL}$ HSD versus an equal volume of Ringer's lactate to patients in the field with severe haemorrhagic shock, who were then transported by helicopter to their emergency department. The hypertonic solutions were found to be as safe in clinical use as Ringer's, indeed HSD showed the potential to increase survival, and reduced the fluid requirements of patients during the initial 24 hours of the study (49). In a follow-up study HSD was evaluated as a prehospital resuscitation fluid for trauma patients undergoing transport by helicopter to the trauma centre. Any patient with a systolic blood pressure less than or equal to $100 \mathrm{mmHg}$ at any time during transport was randomised into a double-blinded trial to receive either $250 \mathrm{~mL}$ of HSD or Ringer's lactate followed as required by conventional isotonic fluids. Those who received HSD had higher mean blood pressures and required less total fluid administration on admission compared to the Ringer's group. Survival to discharge was similar except where the patient had severe head injuries. In the head injury sub-group, those who received HSD showed a tendency toward improved survival (50).

Vassar et al. also report on a series of hypotensive patients (systolic $\leq 90 \mathrm{mmHg}$ ) transported by ambulance randomised to receive $250 \mathrm{~mL}$ of one of three fluids, HSD, 
$7.5 \%$ hypertonic saline or normal saline followed by conventional fluid therapy as indicated by the patients' condition. Compared to predicted survival rates from the TRISS methodology both hypertonic solutions significantly improved survival (51). In another multicentre, doubleblinded, randomised study of HSD and $7.5 \%$ hypertonic saline in hypotensive patients (systolic $\leq 90 \mathrm{mmHg}$ ) transported by helicopter, Vassar et al. showed that prehospital infusion of hypertonic solutions, followed by conventional fluids as required, increased systolic pressure on admission to hospital and survival to discharge compared to survival predicted by the Major Trauma Outcome Study (MTOS) norms (52). Again head injuries with a GCS of less than eight seemed to benefit the most. In both the last studies, however, there was no discernible additional benefit of the colloid component over hypertonic saline $(7.5 \%)$ alone. In their analysis of the potential risks of HSD they stated that detecting the beneficial effects of HSD over conventional therapy was difficult due to the short transport times and the ability to gain intravenous access and to administer large amounts of fluid at rapid rates. In addition, these limited trials required the infusion of large volume Ringer's lactate following the single $250 \mathrm{~mL}$ aliquot of HSD. They concluded that HSD would be most beneficial in the pre-hospital environment where infusion of large volumes of fluid is not possible (53).

In another multicentre clinical trial in the US to evaluate the efficacy and safety of HSD, 422 hypotensive (systolic $\leq 90 \mathrm{mmHg}$ ) trauma patients transported by ambulance to three urban medical centres were enrolled. The patients received either $250 \mathrm{~mL} \mathrm{HSD}$ or Ringer's followed by Ringer's lactate as required in the pre-hospital phase. The results showed that survival was significantly improved in the HSD group who required surgery (91\% versus $79 \%$ ), but overall 24 hour survival rates were not significantly different (54). Younes et al., however, in an emergency room study of $250 \mathrm{~mL} \mathrm{HSD}$ or normal saline reported that 24-hour and 30day survival was significantly higher in those patients who received HSD on admission. Only patients who had a mean arterial pressure of less than $70 \mathrm{mmHg}$ on admission benefitted significantly from the HSD (55).

Wade et al., noting that individual trials of small-volume resuscitation using $7.5 \% \mathrm{NaCl}$ with and without $6 \%$ dextran 70 in traumatic haemorrhage had failed to provide convincing evidence of efficacy, performed a meta-analysis of summary data to determine the effect of hypertonic saline or HSD on survival. The discharge data of eight randomised, double-blind trials of HSD and six similar trials involving hypertonic saline were analysed. They found that hypertonic saline alone was ineffective in improving survival over the standard of care solution, but that HSD may be superior, with an increase in survival to discharge, or to 30 days, in seven out of eight trials. This result, however, did not reach significance (56). In another meta-analysis of individual patient data by the same authors (unpublished) HSD was shown to be more effective than standard of care solutions when HSD was administered as the initial fluid but its effect diminished below significance when patients received large volume isotonic crystalloid prior to HSD.

\section{Safety}

Hypertonic solutions have the potential to cause hypernatraemia and to cause disorientation, confusion, convulsions, hyperchloraemic acidosis and central pontine myelinolysis. The addition of dextrans into this solution has raised concerns in the medical community related to the longpublicised side effects of the early formulations of dextrans. These include causing difficulties in cross-matching and anaphylactoid reactions, interfering with coagulation and impairing renal function. Other problems include irritation on peripheral administration and the potential of HSD to exacerbate problems in dehydrated or heat-stressed patients. Furthermore, animal studies have shown that multiple doses of HSD may be deleterious and rapid bolus infusion can cause transient hypotension. However, by far the most dangerous effect of the administration of HSD in the pre-hospital scenario is the induction of rebleeding in uncontrolled haemorrhage. All of these several points will be covered in more detail below.

There is a substantial body of toxicological testing of HSD in animals in support of the New Drug Application to the Food and Drug Administration in the US that shows that HSD is no more irritant than Ringer's lactate (57). All the components of HSD were individually assessed for acute and subacute toxicity and the maximum tolerated dose. Studies involving the use of the maximum tolerated dose of $16-20 \mathrm{~mL} / \mathrm{kg}$, depending on the animal, (which is 4-5 times the human dose), showed that there were unlikely to be allergic complications (58) or adverse effects on renal function (59). Elevations in serum sodium were, on average, up $12 \mathrm{mEq} / \mathrm{L}$ and some animals showed a rise to above $160 \mathrm{mEq} / \mathrm{L}$ but these levels were transient and there were no overt behavioural effects $(14,19)$. In vitro tests of very high concentration HSD and human blood have shown no effect on $\mathrm{ABO}, \mathrm{Rh}$ and $\mathrm{MN}$ typing in fresh and old stored blood, no lysis of erythrocytes and no effect on the metabolic activity of the cells (60). Similarly there was only a slight prolongation of the prothrombin time and decreased platelet 
aggregation on in vitro clotting studies at equally high concentrations of HSD (61). Such slight alterations were not thought to be clinically relevant.

In clinical trials, infusion of $4 \mathrm{~mL} / \mathrm{kg}$ HSD in the pre-hospital phase, in the emergency room or operating theatre, have led to statistically significant elevations in plasma sodium and chloride concentrations and higher osmolalities than infusion with Ringer's lactate (49-54). No statistically significant acidosis was detected in any of these studies and all these variables normalised by 24 hours in one trial (54), and Vassar reports that chemical abnormalities resolve within four hours (20). There were no reported adverse effects related to the hypernatraemic, hyperchloraemic and hyperosmotic state in these studies. No anaphylactoid reaction, dextran-induced coagulopathy or exacerbated bleeding was noted in the US multicenter trial (54). It is, however, known that large doses of dextran 70 (more than $1.5 \mathrm{~g} / \mathrm{kg} /$ day compared to $0.25 \mathrm{~g} / \mathrm{kg}$ of dextran in a normal dose of HSD) can depress factor VIII and will prolong bleeding time (62). No difficulty in cross-matching blood was observed in the emergency room trials (53) and in several studies involving nearly 35,000 patients there is a reported incidence of anaphylactoid reactions of $0.003-0.025 \%(63,64)$.

HSD works by drawing water from within the cells into the extracellular space and then into the vascular compartment. Consequently HSD infusion where there is pre-existing dehydration may be deleterious. This potential contraindication has been investigated in animals with long-term follow-ups, and in moderately dehydrated haemorrhaged pigs (65) and sheep (66) survival improved on administration of HSD without being compromised by dehydration. In fact HSD has been used to effectively treat experimental dehydration (67). There were no adverse neurological or behavioural effects and another study demonstrated that HSD was equally as effective in dehydrated haemorrhaged sheep as in euhydrated, haemorrhaged sheep (68). In a study involving hyperthermic, dehydrated rats, HSD was better than normal saline for the treatment of heat stroke (69).

The effect of giving more than one aliquot of HSD has not been investigated in humans as, in the clinical trials involving traumatic haemorrhage, a single $250 \mathrm{~mL}$ infusion of HSD was invariably followed by further resuscitation with a conventional isotonic fluid. In one pig uncontrolled haemorrhage study, two $250 \mathrm{~mL}$ aliquots of HSD were administered in the resuscitation phase separated by three or six hours. In both cases the second dose caused only limited improvements in haemodynamic stability, possibly due to sustained alterations in sodium homeostasis and a diuresis (70). In anaesthetised animal studies acute hypotension has been induced by the rapid infusion of hypertonic saline. This is thought to be due to a vasodilatory effect in the peripheral circulation, rather than in the heart, as coronary blood flow and cardiac output are increased (71). This suggests that HSD should be infused over at least five minutes.

It is noteworthy that the indications for HSD state that it is for initial treatment of hypovolaemia with hypotension induced by traumatic injury after primary stabilisation of respiration and bleeding (11). This precaution precludes its use in the pre-hospital environment where hypovolaemic trauma patients are assumed to have uncontrolled haemorrhage (unless the bleeding is compressible). This safe approach would seem to be borne out by the experimental animal studies on uncontrolled haemorrhage (9,39-46), however, all the pre-hospital studies involving the use of HSD in trauma and haemorrhage have shown that it is safe in this role and may even improve survival to discharge, despite increasing the blood pressure. It is this concern that leads this author to suggest that HSD is infused more slowly than that recommended in the product information, over 10-20 minutes or, better still, titrated to a palpable radial pulse (vide infra).

\section{HSD in other clinical roles}

HSD, as already mentioned, has been used successfully for the treatment of burns (47) and this article has already alluded to the potential of HSD in traumatic brain injury (TBI). Head injury is the leading cause of mortality in the 24 hours following trauma in the US, accounting for $40-50 \%$ of deaths, closely followed by exsanguination with 30$35 \%$ (72). Traumatic brain injury is a contributing factor in over $60 \%$ of trauma related deaths (73). The primary goals of acute resuscitation of a patient with TBI are to maintain an adequate systolic blood pressure while attenuating any rise in intracranial pressure.

Animal studies have demonstrated that, following focal brain injury and haemorrhagic shock, HSD improved cerebral blood flow with a lower intracranial pressure compared to Ringer's lactate $(74,75)$. In a focal brain injury and inflation of an epidural balloon to enhance intracranial hypertension, HSD and mannitol both lowered intracranial pressure, but HSD, by increasing the blood pressure, improved the cerebral perfusion pressure; mannitol, on the other hand, tended to lower the blood pressure $(76,77)$. Berger et al. also demonstrated that HSD causes a dehydration of the contralateral hemisphere that more than compensates for the small increase in water content of the injured brain tissue. No difference in water content was observed in 
either hemisphere following mannitol administration. Hartl et al., using intra-vital fluorescence video-microscopy to visualise the pial vessels, demonstrated that HSD prevents the increase in arteriolar diameters following a focal fluid percussion injury and that leucocyte adhesion is reduced by $90 \%$ (78).

Vassar et al. have shown after subgroup analysis in three trials that HSD shows a tendency to improve survival in patients with TBI (50-52). These studies are, however, difficult to interpret because of inconsistencies in the fluid regimen used, the control group fluid and the limited sample sizes as well as the presence of other, multiple traumatic injuries. Wade et al. used these studies to perform a meta-analysis to evaluate the effect of HSD on patients with TBI and a systolic blood pressure of 90 $\mathrm{mmHg}$ or less. After adjusting for the confounding variables he found that the 24 hour survival and survival to discharge was statistically higher, by a factor of two, in TBI patients receiving HSD compared to the standard of care solution (79).

Ongoing work by Kirkman et al. (unpublished - personal communication) will show that HSD is a suitable fluid for the resuscitation of haemorrhage following primary blast injury in his rat model of controlled haemorrhage. Evaluation of HSD in primary blast injury in a pig model of uncontrolled haemorrhage is also planned.

Routes of administration of HSD HSD has been shown to be equally effective when administered via the intraosseous route in both human and animal studies. In an experimental project with pigs Dubick et al. observed complete, rapid vascular entry of all components of HSD following intraosseous infusion. They also noticed similar plasma volume expansion and cardiovascular indices in these animals compared to others infused via the intravenous route (80). ChavezNegrete et al. used HSD in 10 emergency patients with acute gastrointestinal haemorrhage and hypotension. All patients showed the expected improvement in blood pressure and urine output and the overall results were indistinguishable from those given HSD intravenously (81). These results support the potential use of HSD via the intraosseous route as an alternative where vascular access is difficult or unobtainable.

\section{The case for HSD in BATLS}

The BATLS didactic algorithm stresses the vital importance of recognising the need for surgery in the control of haemorrhage, especially when a shocked casualty has incompressible bleeding (82). As Chisolm said in the American Civil War, "The finger pressure of an intelligent assistant is better than any tourniquet ever made, and is a far preferable means of controlling excessive haemorrhage" (83). However, on the battlefield immediate evacuation of a casualty with traumatic incompressible haemorrhagic hypovolaemia may not be available, in which case intravenous access should be obtained and fluid infused as required to maintain a palpable radial pulse. Isotonic crystalloid is stated as the resuscitation fluid in this regime of hypotensive resuscitation. Currently, the Consensus Working Group on Pre-Hospital Fluids recommends resuscitation with normal saline (84).

On the battlefield, administration of large volumes of intravenous fluid of any type is beset with difficulties. Establishing large bore intravenous access may be impossible due to established shock and a cold environment. Combat clothing and equipment has to be negotiated to expose a site of venous access. This manoeuvre may have to be accomplished in extremely hostile conditions, for example, under enemy fire and there may be multiple casualties requiring intravenous access for fluid infusion. Furthermore, any attention at all to a casualty may be delayed for tactical reasons. In the event that intravenous access is established in a casualty who requires fluid resuscitation, the sheer volume of fluid required to replace one part blood with three parts crystalloid presents its own problems. It has proved difficult to infuse large volumes through intravenous cannulae in the prehospital environment. In the Falklands War in 1982, the average pre-hospital (pre-role 3) infusion in shocked patients was $500 \mathrm{~mL}$ and on arrival at the role 3 hospital facility 70$80 \%$ of intravenous access was no longer patent (personal communication). Transporting several one-litre bags per potential casualty to the battlefield is a logistic challenge in itself. In addition, reports from Sweden (personal communication) indicate that, in the prehospital environment in winter, one-litre bags of crystalloid are nearly impossible to warm satisfactorily prior to administration. Even when the bags are warmed, (on the engine block of the ambulance, or in specially-built heating compartments in the cabin), patients still become hypothermic as the fluid cools rapidly outside and during its passage through the giving-set. Finally, if all the above obstacles are surmounted, aggressive " $3: 1$ " isotonic resuscitation of uncontrolled haemorrhage as advocated by the ATLS manual will cause rebleeding, increased haemorrhage and decreased survival!

In the austere environment of a battlefield, small volume resuscitation with HSD has several potential advantages over conventional crystalloid solutions. For the same clinical benefit, one part of HSD is equivalent to $10-12$ parts of crystalloid, that is, one $250 \mathrm{~mL}$ bag is physiologically equal to 
three one-litre bags of normal saline. It is much more portable and it is a stable solution without any particular storage precautions. It has a shelf life of 2 years.

In cases of difficulty cannulating a suitable vein for intravenous infusion, systemic access can be achieved via an intraosseous needle developed for adults that is placed into the anterior tibia. In extremis the intraosseous needle/trocar combination can be placed directly through clothing, recognising the potential for infection, or, circumstances permitting, the clothing could be cut to achieve a sterile field. The intraosseous route is probably easier to teach to nonmedical combatants who are most likely to be the first responders on the battlefield.

HSD, in clinical trials, has shown a tendency to improve both early ( 24 hour) and long term survival to discharge. In the case of head injury in poly-trauma it has been shown to confer a statistically significant increase in survival. HSD causes an immediate increase in systemic blood pressure and cardiac output, while reducing vascular resistance by its effect on the microcirculation. There is an increase in nutritional, regional and organ blood flow and a resultant improvement in organ function compared to the same dose of crystalloid. HSD has been shown to reduce post-ischaemic reperfusion injury and reduce immunosuppression and the later complications of multiple organ failure and sepsis. HSD has also been shown to be a useful adjunct to the resuscitation of other battlefield casualties, specifically those with head injuries and burns. The use of HSD following primary blast injury with haemorrhage looks promising from the limited experimental work in this field to date.

There are also potential disadvantages of using HSD. All shocked trauma casualties who require fluid resuscitation must be assumed to have uncontrolled haemorrhage. Too rapid an infusion of $250 \mathrm{~mL}$ HSD (less than two minutes) is not likely to be beneficial as any temporary clots are likely to be disrupted by the increase in systolic pressure, leading to further haemorrhage and a decrease in survival, just as in an aggressive infusion of a large volume of isotonic crystalloid. Small aliquots of HSD, titrated to the presence of a palpable radial (or other) pulse - that is, hypotensive resuscitation with HSD, may well overcome this problem and lead to improved survival rates. Smaller bags of $100 \mathrm{~mL}$ may aid the process of delivering small aliquots of HSD in the battlefield environment where slow infusions may not be practical. The other theoretical disadvantages, such as pre-existing dehydration, electrolyte abnormalities, interference with coagulation and cross-matching, anaphylactoid reactions, and local irritation have all been dealt with above.
Currently HSD is not licensed for use in resuscitation in trauma in the United States. However, at a recent conference entitled "Fluid Resuscitation in Combat" held at the Canadian Defence and Civil Institute of Environmental Medicine in Toronto in 2001, the consensus panel recommended the use of HSD in combat casualty care to the Canadian Armed Forces. The consensus panel suggested one $250 \mathrm{~mL}$ aliquot of HSD to be given slowly, over 10-15 minutes, as the initial fluid of resuscitation, and titrated to the presence of a radial pulse as a first line fluid in the treatment of incompressible haemorrhagic shock with a further dose as required where evacuation is prolonged. Thereafter conventional fluid therapy is to be employed.

In a civilian context, where there are fewer logistic constraints on fluid transport and evacuation time to the trauma centre is less than one hour, the case for HSD in the prehospital phase of patient management is less clear-cut. The several pre-hospital studies show that it is efficacious in this context but significance is difficult to demonstrate.

\section{Conclusions}

The injured battlefield combat casualty has several needs. These are (1) establishing or ensuring and maintaining an adequate airway and breathing, (2) controlling external haemorrhage, and (3) fluid resuscitation of hypovolaemia and shock. In addition the first responder must initiate and facilitate rapid evacuation to deliver live casualties to organised medical care behind the lines of battle. These priorities are set out in detail in the Battlefield Advanced Trauma Life Support Manual (85). This article seeks to stimulate debate about the best fluid for resuscitation of the battlefield combat casualty.

In the absence of an ideal fluid for resuscitation of haemorrhagic shock in the pre-hospital environment and while haemoglobin-based oxygen carrying solutions are still in development, HSD may be the ideal solution. It is a combination of hypertonic crystalloid and hyperoncotic colloid and thus neatly sidesteps the crystalloid - colloid debate. HSD is well positioned as far as the more recent debate over the most appropriate resuscitation strategy. Logistically, in a military context, it is easier to manage than large volume crystalloid in the pre-hospital environment, where the resuscitation strategy debate centres and where the environment conspires to make large volume infusion difficult. Controlled clinical trials are needed to establish if HSD, used in a regimen of hypotensive resuscitation in the pre-hospital treatment of traumatic haemorrhage is preferable to the standard of care (isotonic) solution. Finally, no one would argue that, once in the hospital environment, the best 
treatment for a trauma casualty who continues to haemorrhage is in the operating theatre with the "finger pressure of an intelligent assistant" adequately applied.

\section{Recommendations}

1. The initial resuscitation fluid of battlefield casualties suffering from incompressible haemorrhagic shock (defined by the absence of a palpable radial pulse or a failure to mentate normally) should be an intravenous or intraosseous infusion of $100 \mathrm{~mL}$ HSD delivered over 5 minutes. Further aliquots should be administered similarly, as required, to maintain the presence of the radial pulse. Futher research is required to determine the efficacy of administering more than $2 \times 100 \mathrm{ml}$ aliquots before conventional fluid therapy is started.

2.If accessible, all severely injured battlefield casualties, especially those with incompressible haemorrhage, should be evacuated to an organised medical facility behind the lines with the minimum delay.

\section{References}

1. Velanovich V. Crystalloid versus colloid fluid resuscitation: a meta-analysis of mortality. Surgery 1975; 78: 291-303.

2. Lamke L-O, Liljedahl S-O. Plasma volume changes after infusion of various plasma expanders. Resuscitation. 1976; 5: 93-102.

3. Tønnessen T, Tølløfsrud S, Kongsgaard UE, Noddeland H. Colloid osmotic pressure of plasma replacement fluids. Acta Anaesthesiol Scand. 1993; 37: 424-426.

4. Hint H. Relationships between the chemical and physiochemical properties of dextran and its pharmacological effects. Derrick JR, Guest MM, eds. Dextrans: current concepts of basic actions and clinical applications. Springfield IL: Charles C Thomas. 1971: 3-26.

5. Tølløfsrud S, Bjerkelund CE, Kongsgaard UE, Noddeland H. Cold and warm infusion of Ringer's lactate in healthy volunteers: the effects on haemodynamic parameters, transcapillary fluid balance, diuresis and atrial peptides. Acta Anaesthiol Scand 1993; 37: 768-773.

6. Wiggers CJ. Physiology of shock. New York: Commonwealth Fund. 1950; pp121-126.

7. Shires GT, Coln D, Carrico J. Fluid therapy in haemorrhagic shock. Arch Surg 1964; 88: 688693.

8. American College of Surgeons Committee on Trauma. Advanced Trauma Life Support Program. Chicago 7th ed. 1997.

9. Stern SA, Dronen SC, Birrer P, Wang X. Effect of blood pressure on haemorrhage volume and survival in a near fatal haemorrhage model incorporating a vascular injury. Ann Emerg Med 1995; 22: 155-163.

10. Bickell WH, Wall MJ, Pepe PE, et al. Immediate versus delayed fluid resuscitation for hypotensive patients with penetrating torso injuries. N Engl f Med 1994; 331: 1105-1109.

11. Horizon lifecare. RescueFlow ${ }^{\circledR}$ Product Information. 2001.

12. Michel CC. Flow of water through the capillary wall. In: Ussing $\mathrm{HH}$. ed. Water transport across epithelia. Copenhagen: Munksgaard. 1981.

13. Mazzoni MC, Borgstrom P, Arfors KE, Intaglietta M. Dynamic fluid redistribution in hyperosmotic resuscitation of hypovolaemic haemorrhage. Am $\mathcal{F}$ Physiol. 1988; 255: H629-H637.
14. Kramer GC, Perron PR, Lindsey DC, et al. Smallvolume resuscitation with hypertonic saline dextran solution. Surgery 1986; 100: 239-246.

15. Kramer GC, Nakayama S, Smith GJ, et al. Comparison of hypertonic and isotonic saline resuscitation of haemorrhage hypotension. Circ Shock. 1984; 13: 61.

16. Smith GJ, Kramer GC, Perron, PR, et al. A comparison of several hypertonic solutions for resuscitation of bled sheep. I Surg Res 1985; 39: 517-528.

17. Maningas PA, DeGuzman LR, Tillman FJ, et al. Small volume infusion of $7.5 \% \mathrm{NaCl}$ in $6 \%$ dextran 70 for the treatment of severe haemorrhagic shock in swine. Ann Emerg Med 1986; 15: 1131-1137.

18. Wade CE, Hannon JP, Bossone CA, et al. Resuscitation of conscious pigs following haemorrhage: comparative efficacy of small volume resuscitation. Circ Shock 1989; 29: 193204.

19. Younes RN, Aun F, Accioly CQ, et al. Immediate effects and late outcomes of the treatment of hypovolaemic patients with hypertonic saline: a prospective double-blind study in 105 patients. Surg Forum 1988; 39: 70-72.

20. Vassar MJ, Holcroft JW. Use of hypertonichyperoncotic fluids for resuscitation of trauma patients. F Intensive Care Med 1992; 7: 189-198.

21. Tølløfsrud S, Elijo GI, Prough DS, et al. The dynamics of vascular volume and fluid shifts of infused lactated Ringer's and hypertonic saline dextran (HSD) in normovolaemic sheep. Anaesth Analg 2001; 21(suppl): S143.

22. Baue AE, Tragus ET, Parkins WM. A comparison of isotonic and hypertonic solutions and blood on blood flow and oxygen consumption in the initial treatment of haemorrhagic shock. F Trauma 1967; 7: 743-756.

23. Velasco IT, Pontieri V, Rocha-e-Silva M, Lopes O Hyperosmotic $\mathrm{NaCl}$ and severe haemorrhagic shock. Am $\mathcal{F}$ Physiol 1980; 239: H664-673.

24. Nakayama S, Sibley L, Gunther RA, et al. Small volume resuscitation with hypertonic saline $(2,400$ $\mathrm{mOsm} / \mathrm{L}$ ) during haemorrhagic shock. Circ Shock. 1984; 13: 149-159.

25. Smith GJ, Kramer GC, Perron P, et al. A comparison of several hypertonic solutions for resuscitation of bled sheep. F Surg Res 1985; 38: 180-186.

26. Velasco IT, Oliveira MA, Oliveira MA, et al. A comparison of hyperosmotic and hyperoncotic resuscitation from severe haemorrhagic shock in dogs. Circ Shock 1987; 29: 338.

27. Walsh JC, Kramer GC. Resuscitation of hypovolaemic sheep with hypertonic saline/dextran: the role of dextran. Circ Shock 1991; 34: 336-343.

28. Maningas PA, Volk K, DeGuzman L. Resuscitation with $7.5 \% \mathrm{NaCl} / 6 \%$ dextran 70 during haemorrhagic shock in swine: effect on blood flow. Crit Care Med 1987; 15: 1121-1126.

29. Kreimeier U, Bruckner UB, Niemczyk S, et al. Hyperosmotic saline dextran for resuscitation from traumatic-haemorrhagic hypotension: effect on regional blood flow. Circ Shock 1990; 32: 83.

30. Mazzoni MC, Borgström P, Intaglietta M, et al. Capillary narowing in haemorrhagic shock is rectified by hyperosmotic saline-dextran reinfusion. Circ shock 1990; 31: 407.

31. Mazzoni MC, Borgström P, Intaglietta M, et al. Reopening of shock-narrowed capillaries with reinfusion of $7.5 \% \mathrm{NaCl} / 6 \%$ Dextran-70. Eur Surg Res 1990; 22: 292.

32. Nolte D, Bayer M, Lehr HA, et al. Attenuation of post-ischaemic microvascular disturbances in striated muscle by hyperosmolar saline dextran. Am f Physiol 1992; 263: H1411-H1416.

33. Kreimeier U, Thiel M, Messmer K, Hypertonichyperoncotic solutions. In Risberg B ed. Trauma Care - an update. Stockholm: Pharmacia \& Upjohn Sverige AB. 1996; 142-153. 
34. Junger WG, Coimbra R, Hoyt DB et al. Hypertonic saline activates $\mathrm{T}$-cells and reverses post-traumatic immunosuppression. Int $\mathcal{F}$ Microcirc Clin Exp 1996; 16(suppl 1): 26 (abstract).

35. Reed LL, Manglano R, Martin M et al. The effect of hypertonic saline resuscitation on bacterial translocation after haemorrhagic shock in rats. Surgery. 1991; 110: 685-690.

36. Cannon WB, Frazer J, Cowell EM. The preventative treatment of wound shock. $\mathcal{F} A M A$ 1918; 70: 618-621.

37. Beecher HK. Resuscitation of men severely wounded in battle. DeBakey ME, ed. Surgery in World War II. Vol II: General Surgery. Washington, DC: Office of the Surgeon General, Department of the Army; 1955: 6.

38. Wangensteen SL, Ludewig RM. Bleeding and blood pressure. Am $\mathcal{F}$ Surg 1969; 118: 413-414.

39. Bickell WH, Bruttig SP, Millnamow MA et al. The detrimental effects of intravenous crystalloid after aortotomy in swine. Surgery 1991; 110: 529-536.

40. Gross D, Ezekiel H, Landau $\mathrm{H}$ et al. Quantitative measurement of bleeding following hypertonic saline therapy in "uncontrolled" haemorrhagic shock. F Trauma 1989; 29: 79-83.

41. Gross D, Ezekiel H, Landau $\mathrm{H}$ et al. Is hypertonic saline resuscitation safe in uncontrolled haemorrhagic shock? $\mathcal{F}$ Trauma 1988; 28: 751756 .

42. Kowalenko T, Stern S, Dronen, S, Wang X. Improved outcome with hypotensive resuscitation of uncontrolled haemorrhagic shock in a swine model. F Trauma 1992; 33: 349-353.

43. Stern SA, Dronen SC, Wang X. Multiple resuscitation regimens in a near-fatal porcine aortic injury haemorrhage model. Acad Emerg Med 1995; 2: 89-97.

44. Capone AC, Safar P, Stezoski W et al. Improved outcome with fluid restriction in treatment of uncontrolled haemorrhagic shock. $\mathcal{F}$ Am Coll Surg 1995; 180: 49-56.

45. Doucet JJ, Hall RI. Limited resuscitation with hypertonic saline, hypertonic sodium acetate, and lactated Ringer's solutions in a model of uncontrolled haemorrhage from a vascular injury. F Trauma 1999; 47: 956-963.

46. Burris D, Rhee P, Kaufmann C et al. Controlled resuscitation for uncontrolled haemorrhagic shock. F Trauma 1999; 46: 216-223.

47. Monafo WW, Chuntrasakul C, Ayvazian VH. Hypertonic sodium solutions in the treatment of burn shock. Am F Surg 1974; 126: 773-783.

48. Shackford SR, Sise MJ, Fridlund $\mathrm{PH}$ et al. Hypertonic sodium lactate Ringer's solution for intravenous fluid therapy in operations on the abdominal aorta. Surgery 1983; 94: 41-51.

49. Holcroft JW, Vassar MJ, Turner JE et al. $3 \% \mathrm{NaCl}$ and $7.5 \% \mathrm{NaCl} /$ dextran 70 in the resuscitation of severely injured patients. Ann Surg 1987; 206: 279-288.

50. Vassar MJ, Perry CA, Gannaway WL, Holcroft JW. $7.5 \%$ sodium chloride/dextran for resuscitation of trauma patients undergoing helicopter transport. Arch Surg 1991; 126: 1065-1072.

51. Vassar MJ, Perry CA, Holcroft JW. Prehospital resuscitation of hypotensive trauma patients with $7.5 \% \mathrm{NaCl}$ versus $7.5 \% \mathrm{NaCl}$ with added dextran: a controlled trial. F Trauma 1993; 34: 622-633.

52. Vassar MJ, Fischer RP, O'Brien PE et al. A multicentre trial for resuscitation of injured patients with $7.5 \%$ sodium chloride. The effect of added dextran 70. Arch Surg 1993; 128: 10031013.

53. Vassar MJ, Perry CA, Holcroft JW. Analysis of potential risks associated with $7.5 \%$ sodium chloride resuscitation of traumatic shock. Arch Surg 1990; 125: 1309-1315.

54. Mattox KL, Maningas PA, Moore EE et al. Prehospital hypertonic saline/dextran infusion for post-traumatic hypotension: the U.S.A. multicentre trial. Ann Surg 1991; 213: 482-491.
55. Younes RN, Aun F, Ching CT et al. Prognostic factors to predict outcome following the administration of hypertonic/hyperoncotic solution in hypovolaemic patients. Shock 1997; 7: 79-83.

56. Wade CE, Kramer GC, Grady JJ et al. Efficacy of hypertonic $7.5 \%$ saline and $6 \%$ dextran-70 in treating trauma: a meta-analysis of controlled clinical studies. Surgery 1997; 122: 609-616.

57. Hands R, Holcroft JW, Perron PR et al. Comparison of peripheral and central infusions of $7.5 \% \mathrm{NaCl} / 6 \%$ dextran-70. Surgery 1988; 103: 684 .

58. Summary JJ, Dubick MA, Zaucha GM et al. Acute and subacute toxicity of $7.5 \%$ hypertonic saline $/ 6 \%$ dextran-70 (HSD) in dogs: 1 . Serum immunog-lobulin and complement responses. $f$ Appl Toxicol 1992; 12: 261.

59. Dubick MA, Zaucha GM, Korte Jr DW et al. Acute and subacute toxicity of $7.5 \%$ hypertonic saline $6 \%$ dextran-70 (HSD) in dogs: 2 Biochemical and behavioural responses. I Appl Toxicol 1993; 13: 49.

60. Moore GL, Summary JJ, Drace C et al. The effects of hypertonic saline $(7.5 \%)$ / dextran 70 (HSD) on human red cell typing, lysis and metabolism in vitro. Vox Sang 1990; 59: 227.

61. Hess JR, Dubick MA, Summary JJ et al. The effects of $7.5 \% \mathrm{NaCl} / 6 \%$ dextran 70 (HSD) on coagulation and platelet aggregation in humans. $\mathcal{f}$ Trauma 1992; 32: 40.

62. Isbister J, Fischer M. Adverse effects of plasma expanders. Anaesth Intensive Care 1980; 8: 145151.

63. Ring J, Messmer K. Incidence and severity of anaphylactic reactions to colloid volume substitutes. Lancet 1977; 1: 466-469.

64. Ljungstrom K-G, Renck H, Strandberg K, et al. Adverse reactions to dextran in Sweden. Acta Circ Scand 1983; 149: 253-262

65. Wade CE, Tillman FJ, Loveday JA et al. Effects of dehydration on cardiovascular responses and electrolytes after hypertonic saline/dextran treatment for moderate haemorrhage. Ann Emerg Med 1992; 21: 112.

66. Sondeen JL, Gunther RA, Wade CE et al. Hypertonic saline/hyperoncotic dextran (HSD) does not raise plasma sodium (PNA) nor osmolality (POSMO) excessively in dehydrated $(\mathrm{DEH})$ conscious sheep following haemorrhage (HEM). Circ Shock 1992; 37: 10.

67. Gunther RA, Perron PR, Nguyen MT et al. Dehydration and the cardiovascular response to hypertonic saline/dextran resuscitation in sheep. Eur Surg Res 1990; 22: 292.

68. Matthew C, Durkot M, Patterson D. Fluid shift induced by $7.5 \%$ sodium chloride in $6 \%$ dextran 70 (HSD) in dehydrated swine. Circ Shock 1993; 41: $150-155$.

69. Matthew CB. Treatment of hyperthermia and dehydration with a hypertonic saline in dextran. Shock 1994; 2: 216-221.

70. Stapley SA, Clasper JC, Horrocks CL et al. Repeated dosing with hypertonic saline dextran (HSD) in a model of uncontrolled haemorrhage causes sustained alterations in sodium haemostasis. Shock 2000; 13(suppl): 137 (abstract).

71. Kein ND, Kramer GC, White DA. Acute hypotension caused by rapid hypertonic saline infusion in anaesthetised dogs. Anaesth Analg 1991; 73: 597-602.

72. Sauaia A, Moore FA, Moore EE et al. Epidemiology of trauma deaths: a reassessment. J Trauma 1995; 38: 185-193.

73. Shackford SR, Mackersie RC, Davis JW et al. Epidemiology and pathology of traumatic deaths occuring at a Level 1 trauma center in a regionalized system: the importance of secondary brain injury. F Trauma 1989; 29: 1392-1397.

74. Walsh JC, Zhuang J, Shackford SR. A comparison of hypertonic to isotonic fluid in the resuscitation of brain injury and haemorrhagic shock. F Surg Res 1991; 50: 284-292. 
75. Shackford SR. Effect of small-volume resuscitation on intracranial pressure and related cerebral variables. F Trauma 1997; 42(suppl 5): S48-S53.

76. Berger S, Schurer L, Hartl R et al. Reduction of post-traumatic intracranial hypertension by hypertonic/hyperoncotic saline/dextran and hypertonic mannitol. Neurosurgery 1995; 37: 98107.

77. Berger S, Schurer L, Hartl R, et al. $7.2 \%$ $\mathrm{NaCl} / 10 \%$ dextran 60 versus $20 \%$ mannitol for treatment of intracranial hypertension. Acta Neurochir Suppl 1994; 60: 494-498.

78. Hartl R, Medary MB, Ruge $\mathrm{M}$ et al. Hypertonic/hyperoncotic saline attenuates microcirculatory disturbances after traumatic brain injury. F Trauma 1997; 42(suppl 5): S41S47.

79. Wade CE, Grady JJ, Kramer GC et al. Individual patient cohort analysis of the efficacy of hypertonic saline/dextran in patients with traumatic brain injury and hypotension. F trauma 1997; 42(suppl): S61-S65.
80. Dubick MA, Pfeiffer JW, Clifford CB et al. Comparison of intraosseous and intravenous delivery of hypertonic saline/dextran in anaesthetised euvolaemic pigs. Ann Emerg Med 1992; 21: 498.

81. Chavez-Negrete A, Majluf Cruz S, Frati Munari A et al. Treatment of haemorrhagic shock with intraosseous or intravenous infusion of hypertonic saline dextran solution. Eur Surg Res 1991; 23: 123.

82. Army Medical Directorate [Resources and Plans]. Battlefield Advanced Trauma Life Support (BATLS). I R Army Med Corps 2001; 147: 187194.

83. Chisholm JJ. A manual of military surgery for the use of surgeons in the Confederate States Army. Columbia, SC Evans \& Cogswell. 1864.

84. Consensus Working Group on Pre-Hospital Fluids. Fuid resuscitation in Pre-hospital Trauma Care: a consensus view. F R Army Med Corps 2001; 147: 147-152.

85. Army Medical Directorate [Resources and Plans]. Battlefield Advanced Trauma Life Support Manual. 2nd ed. 2000; D/AMD/113/23: Army Code no 63726 . 